\title{
Work Passion e Identidade: reflexões de uma meta-síntese
}

Work Passion and Identity: reflections from a meta-synthesis

\author{
Samantha Frohlich ${ }^{1}$ (D), Adriana Roseli Wunsch Takahashi ${ }^{2}$ (D) \\ ${ }^{1}$ Universidade Federal do Paraná (UFPR), Brasil, Doutoranda em Administração (UFPR), professora colaboradora no curso de \\ Secretariado Executivo Trilíngue (Unioeste), e-mail: samantha_0906@ hotmail.com \\ ${ }^{2}$ Universidade Federal do Paraná (UFPR), Brasil, Doutora em Administração (FEA/USP), professora titular nos cursos de \\ doutorado, mestrado e graduação em Administração (UFPR), e-mail: adrianarwt@ gmail.com
}

\section{RESUMO}

O presente estudo tem como objetivo analisar como a Work Passion afeta na Identidade dos indivíduos em suas atividades, aos quais foram analisados estudos de caso a partir da metodologia de meta-síntese proposta por Hoon (2013). Considerando esses dois conceitos, ressalta-se que para Vallarand et al., (2003) a paixão pelo trabalho existe quando as pessoas julgam importantes ou investem tempo e energia na atividade. Nesse sentido, as atividades de valor passam a ser internalizadas na identidade da pessoa. Para alcançar os resultados foram feitas buscas em quatro bases de dados: Web of Science, Scielo, Spell e Scopus, em que os termos utilizados para busca foram "Work Passion*" AND "Identity" AND "Study Case". A síntese realizada neste estudo contribuiu para o avanço da literatura em Work Passion e Identidade ao propor um conjunto básico de características presentes nos artigos analisados aos quais chama-se atenção para o tema e suas variáveis, avançando principalmente no estudo da literatura do tema tornando-se útil para futuros estudos.

Palavras-chave: Meta síntese. Work Passion. Identidade. Estudo de Caso.

\begin{abstract}
The present study aims to analyze how Work Passion affects the Identity of individuals in their activities, to which case studies were analyzed from the meta-synthesis methodology proposed by Hoon (2013). Considering these two concepts, it is noteworthy that for Vallarand et al. (2003) the passion for work exists when people consider it important or invest time and energy in the activity. In this sense, the valuable activities become internalized in the person's identity. To reach the results, searches were made in four databases: Web of Science, Scielo, Spell and Scopus, in which the terms used for the search were "Work Passion*" AND "Identity" AND "Study Case". The synthesis performed in this study contributed to the advancement of the literature on Work Passion and Identity by proposing a basic set of characteristics present in the analyzed articles to which attention is drawn to the theme and its variables, advancing mainly the study of the literature on the subject, making it useful for future studies.
\end{abstract}

Keywords: Meta-Synthesis. Work Passion. Identity. Case Study. 


\section{INTRODUÇÃO}

O estudo de caso nos permite visualizar os fenômenos organizacionais em um ambiente de vida real trazendo uma história rica em detalhes. Estudos de caso qualitativos tem alento para produzir novos conhecimentos teóricos, gerando contribuições para diferentes pesquisas tornando os dados de pesquisas primária públicos (STAKE 2005; YIN 2009, HOON, 2013).

A meta-síntese nos estudos qualitativos não é muito comum, mas oferece ao pesquisador um conjunto de opções metodológicas e procedimentos que tem por objetivo aumentar o potencial da prática teórica. Nesse sentido, o conjunto de estudos de caso dão uma visão empírica ao desenvolvimento do conhecimento da pesquisa em gestão, oferecendo descobertas detalhadas, permite verificar-se o ritmo da produção do conhecimento em determinado tema e uma generalização analítica contribuindo para o aperfeiçoamento da teoria (HOON, 2013).

Conforme a proposta de Hoon (2013), seguiu-se oito passos metodológicos com o objetivo de analisar-se estudos de caso qualitativos para fornecer evidências ao fenômeno estudado, neste caso, como os conceitos de Work passion e Identidade se relacionam. As fases do estudo são as seguintes: enquadramento da pergunta de pesquisa; localização de pesquisas relevantes; critérios de inclusão e exclusão dos artigos; interpretação e codificação dos dados; análise em nível individual de cada estudo; síntese em nível específico de cada caso, construção teórica e por último, a discussão a respeito dos achados.

Consoante a isso, cabe salientar que a meta-síntese foi escolhida por ser capaz de proporcionar maior compreensão dos temas de Work Passion e Identidade, com o objetivo de entender como eles se relacionam no contexto organizacional. Portanto, a questão de pesquisa escolhida foi: Como a Work Passion e a Identidade interligam-se nos estudos de caso qualitativos analisados a partir da metodologia de meta-síntese proposta por Hoon (2013) ? Dessa forma, pretende-se avançar na área de conhecimento por meio da contribuição teórica alcançada neste trabalho, além de instigar novas pesquisas sobre a temática de Work passion. Salienta-se ainda que este estudo se trata de um recorte de uma pesquisa maior em andamento.

Revista Expectativa, Toledo/PR, v.20, n. 3, p. 131-151, jul./set., 2021. 


\section{REFLEXÕES TEÓRICAS}

O conceito de paixão é antigo na história da filosofia, mas o conceito de paixão por uma atividade específica é recente principalmente dentro do contexto de trabalho nos estudos organizacionais. Essa atividade apaixonada que resulta na própria paixão pelo trabalho pode acontecer de várias formas: seja por interesses pessoais, comprometimento ou prazer pela atividade. O que esses conceitos têm em comum são o compromisso e valor que o indivíduo dispõe para determinada atividade (FOREST et al., 2010).

Para Vallerand et al. (2003), a paixão pelo trabalho relaciona-se à dedicação que as pessoas desenvolvem em relação à uma atividade que gostem, julguem importante ou invistam tempo e energia, tornando-a uma atividade com significados que pode passar a fazer parte da identidade da pessoa, além de serem internalizadas por meio dos seus significados e propósitos. Essa ideia de valor é importante pois separa as atividades apaixonadas das não apaixonadas diferenciado a motivação atrelada a cada uma delas (FOREST et al., 2010). Consoante a isso, destaca-se que a prática do trabalho não pode ser dissociada das emoções das pessoas, uma vez que a atividade humana não é apenas aquilo que é realizado, mas também o que não se realiza e continua a agir interferindo na subjetividade do indivíduo (CLOT, 2007; 2010).

Em reflexo a isso, quando a paixão passa a fazer parte da identidade da pessoa, concordando com o entendimento de Castells (2013) que os papéis organizam funções e atribuem significado à identidade, relacionando este entendimento a work passion, o trabalho passaria também a compor e dar significado a identidade pessoal. Quando as pessoas se identificam fortemente com seus papéis, estes podem também, mesmo de forma transitória, comporem a sua identidade (LOURENÇO DE ABREU, 2020). Essas tensões entre os diversos papéis e a identificação intensa, expressam a "entrega" e a "identificação" das pessoas ao trabalho. A construção da identidade também pode ser entendida como um processo de autoconhecimento envolvendo as relações e o contexto em que um indivíduo se encontra inserido, atrelando-se principalmente aos papéis que este desempenha (SIMPSON; CARROLL, 2015) indo de encontro com a internalização do indivíduo com a paixão.

Quando determinada atividade se torna parte da identidade da pessoa, divide-se essa atividade apaixonada como dois resultados do processo de internalização da paixão: o controlado e o autônomo (DECI; RYAN, 2000). No caso de uma internalização autônoma, a

Revista Expectativa, Toledo/PR, v.20, n. 3, p. 131-151, jul./set., 2021. 
atividade permanece sob o controle do indivíduo e leva a uma paixão harmoniosa. Contrário a isso, a internalização controlada leva ao desenvolvimento de uma paixão obsessiva onde a atividade passa a controlar o indivíduo e não o indivíduo controlar a atividade (VALLERAND et al., 2003).

Nesse sentido, a paixão percebida como positiva pode ser discutida como paixão harmoniosa. Em outro sentido, a paixão obsessiva, em que a pessoa perde o controle sobre as suas atividades, e pode passar a trabalhar compulsivamente, a qual tende a causar resultados negativos. Como exemplo, cita-se a pesquisa com bailarinos feita por Akehurst e Oliver (2014) os autores observaram que na paixão obsessiva as pessoas treinavam a dança mesmo como lesões musculares, o que agravava os seus problemas de saúde. Outro aspecto, seria que na paixão obsessiva acontece um desiquilíbrio entre as esferas profissionais, e pessoais, pela obsessiva paixão dedicada ao trabalho. Entretanto, ainda pouco se sabe sobre os efeitos da paixão obsessiva (VALLERAND et al., 2006; VALLERAND, 2008).

Ainda nesta seara, os autores destacam o seguinte: "A paixão harmoniosa tem sido relacionada as emoções positivas e a paixão obsessiva está mais relacionada à vergonha, à cognição e efeito negativo. Entretanto, essa paixão obsessiva também pode ser encarada como motivação e engajamento em determinada atividade" (AKEHURST; OLIVER, 2014, p. 259)

Assim, deve-se compreender que a paixão obsessiva pode se desenvolver associada à dependência que o indivíduo passa a ter por uma atividade de apreço, proporcionando a ele um papel negativo. A paixão obsessiva pode ser associada a emoções negativas como vergonha, ansiedade, agressão compromisso patológico e outros conflitos mesmo dentro de uma atividade apaixonada (VALLERAND et al., 2003; VALLERAND et al., 2008; DONAHUE; RIP; VALLERAND, 2009). Entretanto, os autores buscam provar que uma paixão harmoniosa diante de seu contexto de desenvolvimento pode proporcionar satisfação também em outros domínios da vida, não apenas no que se refere ao trabalho. Portanto, os autores destacam que diante de determinadas situações, a paixão obsessiva tem relação com a dependência e, a satisfação de uma necessidade pode estar positivamente relacionada à paixão obsessiva e, também à paixão harmoniosa (AKEHURST; OLIVER, 2014).

Revista Expectativa, Toledo/PR, v.20, n. 3, p. 131-151, jul./set., 2021. 


\section{PROCEDIMENTOS METODOLÓGICOS}

Assim, considerando o caráter qualitativo da pesquisa (CRESWELL, 2010) verifica-se que essa abordagem ajuda o pesquisador a elaborar sua análise detalhando melhor o seu estudo (STAKE, 1995). Ao considerar-se a revisão de literatura, cabe ao pesquisador identificar e refletir sobre o tópico proposto ao estudo, além de proporcionar insights de como limitar a área da investigação (CRESWELL, 2007).

Inicialmente, foi então identificada uma lacuna teórica acerca dos estudos relacionados à temática em que, partindo-se da literatura, escolheu-se os descritores "Work Passion" AND "Wom*" (com o objetivo de abranger tanto as definições de Womem a e Womam) AND "Study case *" para a busca. Com o propósito de compreender melhor a interação entre estas variáveis, decidiu-se fazer uma meta-síntese de estudos de caso qualitativos sobre um tema pertinente para a tese da autoria a fim de auxiliar no conhecimento sobre o tema. No entanto, no levantamento realizado nas bases de dados Web of Science, Scopus, Spell e Scielo foram levantados somente 9 artigos. Destes, somente 3 tinham cunho de estudo de caso qualitativo não fornecendo a quantidade mínima de casos necessários para desenvolver-se uma metasíntese. Isto demandou uma pesquisa com descritores mais abrangentes, mas que ainda contemplassem a lacuna na teoria. Depois dessas ponderações, chegou-se ao objetivo geral desta pesquisa: Como a Work Passion e a Identidade interligam-se nos estudos de caso qualitativos analisados a partir da metodologia de meta-síntese proposta por Hoon (2013).

Para alcançar esses resultados foram feitas novas buscas em quatro bases de dados e, os termos escolhidos para busca foram "Work Passion*” AND "Identity" AND "Study Case". Foram encontrados artigos completos considerando todos os anos disponíveis, resultando um total de 17 artigos, sendo: Web of Science (16 artigos); Scopus (nenhum); Scielo (1 artigo) e Spell (nenhum). Em seguida, os artigos foram organizados em uma planilha eletrônica para verificação de trabalhos comuns às bases. Não houve trabalhos repetidos para exclusão resultando em uma amostra de 17 trabalhos.

Para análise dos artigos encontrados, procedeu-se com o desenvolvimento da metasíntese, seguindo o protocolo de oito passos propostos por Hoon (2013) assim como os procedimentos metodológicos, conforme apresentado no Quadro 1. Uma meta-síntese é uma metodologia emergente que por meio de estudos primários valoriza a evidência científica da investigação qualitativa (PINHO et al., 2014). Os autores destacam que os estudos de caso

Revista Expectativa, Toledo/PR, v.20, n. 3, p. 131-151, jul./set., 2021. 
qualitativos foram sintetizados para a realização da extração de uma análise síntese das evidências qualitativas para a construção de uma teoria buscando contribuir para além dos estudos revisados (HOON, 2013).

Quadro 1- Protocolo da meta-síntese

\begin{tabular}{|c|c|c|c|c|}
\hline \multicolumn{2}{|c|}{ Fases } & \multirow[b]{2}{*}{$\begin{array}{l}\text { Meta Analítica } \\
\text { Incorporar conceitualmente a } \\
\text { meta-síntese no campo da } \\
\text { pesquisa sobre Work Passion } \\
\text { e Identidade; encontrar uma } \\
\text { questão de pesquisa clara } \\
\text { abordando quais conceitos de } \\
\text { Work Passion fazem parte da } \\
\text { identidade são usados na } \\
\text { pesquisa sobre o tema. }\end{array}$} & \multirow{2}{*}{$\begin{array}{l}\text { Estratégia/Procedimento } \\
\text { analítico utilizado }\end{array}$} & \multirow{2}{*}{$\begin{array}{l}\text { Resultados que } \\
\text { contribuem para a teoria } \\
\text { Elaborar uma boa pergunta } \\
\text { de pesquisa facilita a } \\
\text { escolha dos critérios de } \\
\text { inclusão e exclusão e a } \\
\text { identificação de uma lacuna } \\
\text { teórica. }\end{array}$} \\
\hline 1 & $\begin{array}{l}\text { Elaboração } \\
\text { da pergunta } \\
\text { de pesquisa }\end{array}$ & & & \\
\hline 2 & $\begin{array}{l}\text { Localizando } \\
\text { pesquisas } \\
\text { relevantes }\end{array}$ & $\begin{array}{l}\text { Identificar as pesquisas sobre } \\
\text { Work Passion e Identidade } \\
\text { são relevantes para a questão } \\
\text { de pesquisa e evitar a } \\
\text { exclusão de dados } \\
\text { importantes. }\end{array}$ & $\begin{array}{l}\text { Pesquisa com as palavras- } \\
\text { chave: "Work Passion" no } \\
\text { título e "Identity" e "study } \\
\text { case*" no tópico sem } \\
\text { restrição de ano nas bases } \\
\text { de dados Web of Science, } \\
\text { Spell, Scopus e Scielo. }\end{array}$ & $\begin{array}{l}\text { Foram localizados } 17 \\
\text { (dezessete) artigos nas bases } \\
\text { procuradas } \\
1 \text { (uma) publicação por } \\
\text { meio de } \\
\text { congressos/conferências e } \\
16 \text { (dezesseis) em } 16 \\
\text { (dezesseis) diferentes } \\
\text { revistas acadêmicas. }\end{array}$ \\
\hline 3 & $\begin{array}{l}\text { Critérios de } \\
\text { inclusão }\end{array}$ & $\begin{array}{l}\text { Elencar critérios para incluir } \\
\text { as publicações alinhadas em } \\
\text { termos do método, foco de } \\
\text { pesquisa, questão de pesquisa } \\
\text { inicial e qualidade. }\end{array}$ & $\begin{array}{l}\text { Elaboração de uma lista } \\
\text { com } 3 \text { (três) critérios de } \\
\text { inclusão e suas } \\
\text { justificativas, deixando } \\
\text { claro os critérios de } \\
\text { exclusão. Os } 17 \\
\text { (dezessete) artigos foram } \\
\text { lidos na íntegra e } \\
\text { selecionados de acordo } \\
\text { com os critérios } \\
\text { elaborados. }\end{array}$ & $\begin{array}{l}\text { Das } 17 \text { (dezessete) } \\
\text { publicações encontradas, } \\
\text { foram delimitadas } 6 \text { (seis) } \\
\text { publicações a serem } \\
\text { incorporadas na meta } \\
\text { síntese. }\end{array}$ \\
\hline 4 & $\begin{array}{l}\text { Extraindo e } \\
\text { codificando } \\
\text { dados }\end{array}$ & $\begin{array}{l}\text { Ler e reler cuidadosamente o } \\
\text { texto completo de cada } \\
\text { estudo. Codificar nos estudos } \\
\text { selecionados as características } \\
\text { e os insights de cada estudo. }\end{array}$ & $\begin{array}{l}\text { Desenvolvimento e } \\
\text { realização de um pré-teste } \\
\text { de uma forma de } \\
\text { codificação com múltiplos } \\
\text { códigos pertinentes ao } \\
\text { objetivo da meta-síntese } \\
\text { verificação das } \\
\text { classificações dos } \\
\text { intercodificadores }\end{array}$ & $\begin{array}{l}\text { Ordenar, codificar e } \\
\text { categorizar os dados de } \\
\text { cada estudo. Organizar os } \\
\text { dados para análise e } \\
\text { possibilitar uma visão } \\
\text { específica de cada } \\
\text { publicação e uma visão } \\
\text { geral do conjunto. }\end{array}$ \\
\hline 5 & $\begin{array}{l}\text { Analisando } \\
\text { em um nível } \\
\text { específico } \\
\text { de caso. }\end{array}$ & $\begin{array}{l}\text { Identificar e analisar as } \\
\text { variáveis encontradas em cada } \\
\text { caso que podem estar } \\
\text { relacionadas a como o Work } \\
\text { passion afeta a Identidade }\end{array}$ & $\begin{array}{l}\text { Redes causais elaboradas } \\
\text { para cada caso analisado. }\end{array}$ & $\begin{array}{l}\text { Identificar temas, conceitos } \\
\text { centrais, padrões ou } \\
\text { relacionamentos em cada } \\
\text { estudo e como cada caso } \\
\text { elabora a maneira como o } \\
\text { Work Passion afeta na } \\
\text { Identidade dos indivíduos. }\end{array}$ \\
\hline
\end{tabular}

Revista Expectativa, Toledo/PR, v.20, n. 3, p. 131-151, jul./set., 2021. 


\begin{tabular}{|l|l|l|l|l|}
\hline $\mathbf{6}$ & $\begin{array}{l}\text { Sintetizando } \\
\text { em um nível } \\
\text { de estudo } \\
\text { transversal }\end{array}$ & $\begin{array}{l}\text { Chegar a um padrão geral das } \\
\text { variáveis mesclando as redes } \\
\text { causais de cada caso em uma } \\
\text { rede meta-síntese, } \\
\text { acumulando o } \\
\text { sequenciamento de variáveis } \\
\text { em um nível de estudo } \\
\text { cruzado }\end{array}$ & $\begin{array}{l}\text { Elaboração de redes } \\
\text { causais específicas de } \\
\text { cada caso }\end{array}$ & $\begin{array}{l}\text { Identificação de padrões } \\
\text { lógicos estabelecidos entre } \\
\text { os casos. } \\
\text { Identificação de um padrão; } \\
\text { processamento cognitivo } \\
\text { gerencial como variável } \\
\text { central; classificação das } \\
\text { variáveis para garantir a } \\
\text { validade. }\end{array}$ \\
\hline $\mathbf{7}$ & $\begin{array}{l}\text { Construindo } \\
\text { teoria a } \\
\text { partir da } \\
\text { meta-síntese }\end{array}$ & $\begin{array}{l}\text { Identificar o conceito de Work } \\
\text { Passion que justifica a } \\
\text { maneira como estas afetam a } \\
\text { Identidade. Demonstrar uma } \\
\text { contribuição significativa para } \\
\text { os estudos do tema: Work } \\
\text { Passion e Identidade }\end{array}$ & $\begin{array}{l}\text { Associar os resultados } \\
\text { com a literatura acerca de } \\
\text { Work Passion e } \\
\text { Identidade. }\end{array}$ & $\begin{array}{l}\text { Identificar os conceitos } \\
\text { Work Passion e Identidade } \\
\text { usados e argumentar uma } \\
\text { contribuição para os estudos } \\
\text { da área. }\end{array}$ \\
\hline $\mathbf{8}$ & $\begin{array}{l}\text { Discutir os resultados da meta } \\
\text { síntese e as limitações da } \\
\text { pesquisa. }\end{array}$ & $\begin{array}{l}\text { Discutindo rigor, } \\
\text { confiabilidade e validade }\end{array}$ & $\begin{array}{l}\text { Legitimar a validade e } \\
\text { confiabilidade do } \\
\text { procedimento e atividades } \\
\text { utilizadas }\end{array}$ \\
\hline
\end{tabular}

Fonte: Elaborado pelos autores (2020) através das informações de Hoon (2013).

Após a definição do protocolo da meta-síntese buscou-se apresentar as abordagens estudadas. Assim, de uma maneira simples e prática apresenta-se os passos para a compreensão de como a Work Passion interfere na Identidade nos casos estudados a seguir.

\section{RESULTADOS E DISCUSSÕES}

Os resultados da presente meta-síntese foram organizados e desenvolvidos de acordo com os oito passos sugeridos por Hoon (2013).

\section{Passo 1: Enquadramento da pergunta de pesquisa}

O primeiro passo para Hoon (2013) consiste em estudar a literatura e compatibilidades para uma clara identificação do problema do fenômeno. Essa pergunta de pesquisa norteará o desenvolvimento da mesma, em que cabem algumas considerações que justifiquem tal escolha. Partindo dessa premissa, considerou-se o exposto a respeito de o trabalho ser uma parte importante da vida das pessoas em que estas, passam grande parte da sua vida trabalhando ou treinando para sua profissão. Alguns indivíduos dão tanto valor à profissão a ponto dela se tornar uma vocação, à qual abrange uma importância tão grande que dá sentido à sua existência passando a fazer parte da sua identidade (WRZESNIEWSKI et al., 1997; 2003; MORIN; DASSA, 2006; VALLERAND et al., 2003). A work passion, assunto pretendido a se estudar

Revista Expectativa, Toledo/PR, v.20, n. 3, p. 131-151, jul./set., 2021. 
aqui, busca compreender como o trabalho desafia a paixão como uma fonte de inclinação para uma atividade que as pessoas gostam, assim, ser apaixonado no trabalho é algo internalizado dentro da identidade de uma pessoa (VALLERAND et al., 2003; FOREST et al., 2010.Dessa maneira, em virtude do que fora exposto pela literatura apresentada e do anseio em explorar esses conceitos, realizou-se um estudo norteado pela seguinte questão: Como a Work Passion e a Identidade interligam-se nos estudos de caso qualitativos analisados a partir da metodologia de meta-síntese proposta por Hoon (2013).

\section{Passo 2: Localização de pesquisas relevantes}

Após o enquadramento de uma questão norteadora da presente pesquisa, faz-se necessário a busca por estudos que sejam relevantes ao que se propõe a meta-síntese (HOON, 2013). Com a realização de buscas nas bases Web of Science, Scopus, Spell, Scielo foram identificados 17 artigos (ver Quadro 1) em diversos periódicos, como apresentado na Tabela 1.

Tabela 1 - Periódicos, artigos e ano de publicação

\begin{tabular}{lcc}
\hline Periódicos & Quantidade & Ano \\
\hline BMC public health & 1 & 2019 \\
Frontiers in psychology & 1 & 2019 \\
International journal of gender and entrepreneurship & 1 & 2018 \\
Perspectives-studies in translation theory and practice & 1 & 2018 \\
Australian Journal of Teacher Education (AJTE) & 1 & 2018 \\
Frontiers in Psychology & 1 & 2018 \\
Academy of management journal & 1 & 2017 \\
International journal of cultural studies & 1 & 2017 \\
Journal of business ethics & 1 & 2017 \\
Psychology and ongoing development & 1 & 2016 \\
Ciencia y Enfermeria XX & 1 & 2014 \\
Accounting organizations and society & 1 & 2013 \\
International conference on e-commerce in developing countries (ECDC) & 1 & 2013 \\
European societies & 1 & 2013 \\
Gender and Education & 1 & 2013 \\
Internacional Journal of Cultural Studies & 1 & 2010 \\
Human relations & 1 & 2010 \\
Social psychology quarterly/American sociological association & 1 & 2008 \\
Journal of mediterranean studies & 1 & 2001 \\
\hline Amostra total = 17 & &
\end{tabular}

Fonte: Elaborada pelos autores (2020).

Os artigos encontrados nas buscas estão inseridos em um contexto de publicações sobre o tema entre os anos de 2001 (primeiro registro encontrado) até o ano de 2019. Verifica-se que foi a partir de 2001 que os pesquisadores iniciaram a discussão sobre work passion e identidade.

Revista Expectativa, Toledo/PR, v.20, n. 3, p. 131-151, jul./set., 2021. 
Foram encontrados diversos periódicos de diversas áreas de estudos, tais como Psicologia, Educação, Empreendedorismo, Cultura, Relações Humanas, Saúde e Organizações. Cabe destacar que o intervalo entre os anos de 2013 à 2018 apresentaram uma quantidade maior e considerável de abordagens nessas temáticas tendo diversos artigos publicados nesse contexto. Portanto, os artigos encontrados aplicam-se a critérios de seleção para a abordagem proposta nesta meta-síntese.

\section{Passo 3: Critérios de inclusão}

A terceira fase da meta-síntese segue na função de auxiliar o pesquisador a selecionar os artigos para serem analisados com o objetivo que estes sejam úteis para fornecer a compreensão na busca de novas ideias para pesquisas futuras. Recomenda-se que nesse momento sejam criados critérios de inclusão e exclusão para que o pesquisador consiga ser mais pontual em sua abordagem. Os esforços empregados na análise devem voltar-se para que os artigos selecionados possam contribuir de algum modo ao que se propõe a pesquisa por completo (HOON, 2013). Levando em consideração essas orientações, foram delineados critérios de exclusão e consequente inclusão, conforme apresentado no Quadro 2.

Quadro 2 - Critérios de inclusão e exclusão dos trabalhos

\begin{tabular}{|c|c|c|}
\hline Critério & Descrição & Trabalhos excluídos \\
\hline $\begin{array}{l}\text { Apenas estudos com } \\
\text { conceitos de Work } \\
\text { Passion e Identidade }\end{array}$ & $\begin{array}{l}\text { Abordagens conceituais } \\
\text { ligadas a Work Passion e } \\
\text { Identidade no resumo }\end{array}$ & $\begin{array}{l}\text { Kingsley, J.; Foenander, E.; Bailey, A. (2019); } \\
\text { Ploix, C. (2018); Langevang, T.; Hansen, M.W.; } \\
\text { Rutashobya,L.K. (2018) } \\
\text { Azmat, F.; Rentschle, R. (2014); } \\
\text { Merino, C.F.; Gallardo, R.Y. (2014); } \\
\text { Powell, E.; Baker, T. (2017); }\end{array}$ \\
\hline $\begin{array}{l}\text { Apenas estudos de } \\
\text { caso qualitativo }\end{array}$ & $\begin{array}{l}\text { Artigos que consistam em } \\
\text { estudos de casos } \\
\text { qualitativos, descritos na } \\
\text { metodologia ou que } \\
\text { apresentem tais } \\
\text { características }\end{array}$ & $\begin{array}{l}\text { Obschonka, M.; Moeller, J.; Goethner, M. (2018); } \\
\text { Powell, E.; Baker, T. (2017); } \\
\text { Teimouri, H.; Eshaghi, A.; Moosavi, S.; Eshaghi, A. } \\
\text { (2013); } \\
\text { Boedker, C.; Fong Chua, W. (2013); } \\
\text { Gotsi, M.; Andriopoulos, C.; Lewis, M.W.; Ingram, } \\
\text { A.E. (2010); }\end{array}$ \\
\hline $\begin{array}{l}\text { Apenas artigos com } \\
\text { acesso disponível }\end{array}$ & $\begin{array}{l}\text { Artigos disponíveis para } \\
\text { download }\end{array}$ & $\begin{array}{l}\text { Addeo, F.; Esposito, M. (2015); } \\
\text { Pratt, J. (2001). }\end{array}$ \\
\hline
\end{tabular}

Fonte: Elaborado pelos autores (2020).

Aplicando-se os critérios de inclusão descritos, foram excluídos os trabalhos que não se encaixavam no perfil definido pelos mesmos, resultando em uma quantidade final de 5 artigos, apresentados na Quadro 3.

Revista Expectativa, Toledo/PR, v.20, n. 3, p. 131-151, jul./set., 2021. 
Quadro 3: Artigos incluidos

\begin{tabular}{|l|l|l|}
\hline Autor & Titulo & Periódico \\
\hline $\begin{array}{l}\text { Hahl, K.; Mikulec, E. } \\
\text { (2018); }\end{array}$ & $\begin{array}{l}\text { Student Reflections on Teacher Identity } \\
\text { Development in a Year-long Secondary } \\
\text { Preparation Program }\end{array}$ & $\begin{array}{l}\text { Australian Journal of Teacher } \\
\text { Education (AJTE) }\end{array}$ \\
\hline $\begin{array}{l}\text { Harvey, A.; Shepherd, T. } \\
(2016) ;\end{array}$ & $\begin{array}{l}\text { When Passion Isn't enough: gender, affect } \\
\text { and credibility in digital games design }\end{array}$ & $\begin{array}{l}\text { Internacional Journal of Cultural } \\
\text { Studies }\end{array}$ \\
\hline Stahl, G.; Dale, P. (2013); & $\begin{array}{l}\text { Success on the decks: working-class boys, } \\
\text { education and turning the tables on } \\
\text { perceptions of failure }\end{array}$ & Gender and Education \\
\hline DeNora, T. (2013); & Musicians Make Markets & \begin{tabular}{l} 
European societies \\
\hline Tayson Smith, R. (2008)
\end{tabular} \\
Emotional Labor in Professional Wrestling & $\begin{array}{l}\text { Social psychology } \\
\text { quarterly/American sociological } \\
\text { association }\end{array}$ \\
\hline
\end{tabular}

Fonte: Elaborado pelos autores (2020).

Os artigos descartados estão apresentados no Quadro 4. Destaca-se que no total foram 12 (onze) artigos excluídos.

Quadro 4 - Artigos excluídos

\begin{tabular}{|c|c|c|}
\hline Autor & Título & Periódico \\
\hline $\begin{array}{l}\text { Kingsley, J.; Foenander, } \\
\text { E.; Bailey, A. (2019); }\end{array}$ & $\begin{array}{l}\text { "You feel like you're part of something } \\
\text { bigger": exploring motivations for } \\
\text { community garden participation in } \\
\text { Melbourne, Australia }\end{array}$ & BMC public health \\
\hline $\begin{array}{l}\text { Obschonka, M.; Moeller, } \\
\text { J.; Goethner, M. (2018); }\end{array}$ & $\begin{array}{l}\text { Entrepreneurial Passion and } \\
\text { Personality: The Case of Academic } \\
\text { Entrepreneurship }\end{array}$ & Frontiers in Psychology \\
\hline $\begin{array}{l}\text { Langevang, T.; Hansen, } \\
\text { M.W.; Rutashobya,L.K. } \\
(2018)\end{array}$ & $\begin{array}{l}\text { Navigating institutional complexities: } \\
\text { The response strategies of Tanzanian } \\
\text { female entrepreneurs }\end{array}$ & $\begin{array}{l}\text { International Journal of Gender And } \\
\text { Entrepreneurship }\end{array}$ \\
\hline Ploix, C. (2018); & $\begin{array}{l}\text { Reterritorialization and aesthetic } \\
\text { transformations: the case of Tony } \\
\text { Harrison's Phaedra Britannica and The } \\
\text { Misanthrope }\end{array}$ & $\begin{array}{l}\text { Perspectives-Studies in Translation } \\
\text { Theory and Practice }\end{array}$ \\
\hline $\begin{array}{l}\text { Powell, E.; Baker, T. } \\
(2017) ;\end{array}$ & $\begin{array}{l}\text { In the beginning: identity processes and } \\
\text { organizing in multi-founder nascent } \\
\text { ventures }\end{array}$ & Academy of management journal \\
\hline $\begin{array}{l}\text { Addeo, F.; Esposito, M. } \\
\text { (2015); }\end{array}$ & $\begin{array}{l}\text { Informal learning and identity } \\
\text { formation: a case study of an Italian } \\
\text { virtual community }\end{array}$ & $\begin{array}{l}\text { Psychology and ongoing } \\
\text { development }\end{array}$ \\
\hline $\begin{array}{l}\text { Azmat, F.; Rentschle, R. } \\
(2014) ;\end{array}$ & $\begin{array}{l}\text { Gender and Ethnic Diversity on Boards } \\
\text { and Corporate Responsibility: The } \\
\text { Case of the Arts Sector }\end{array}$ & Journal of business ethics \\
\hline $\begin{array}{l}\text { Merino, C.F.; Gallardo, } \\
\text { R.Y. (2014); }\end{array}$ & $\begin{array}{l}\text { Describing the engagement in primary } \\
\text { Health care nurses }\end{array}$ & $\begin{array}{l}\text { Ciencia y } \\
\text { Enfermeria }\end{array}$ \\
\hline
\end{tabular}

Revista Expectativa, Toledo/PR, v.20, n. 3, p. 131-151, jul./set., 2021. 


\begin{tabular}{|l|l|l|}
\hline $\begin{array}{l}\text { Teimouri, H.; Eshaghi, A.; } \\
\text { Moosavi, S.; Eshaghi, A. } \\
(2013) ;\end{array}$ & $\begin{array}{l}\text { Studying degree of workaholism } \\
\text { among professors in Islamic Azad } \\
\text { Universities of Isfahan Province, Iran }\end{array}$ & $\begin{array}{l}\text { International conference on e- } \\
\text { commerce in developing countries } \\
\text { (ECDC) }\end{array}$ \\
\hline $\begin{array}{l}\text { Boedker, C.; Fong Chua, } \\
\text { W. (2013); }\end{array}$ & $\begin{array}{l}\text { Accounting as an affective technology: } \\
\text { A study of circulation, agency and } \\
\text { entrancement }\end{array}$ & $\begin{array}{l}\text { Accounting Organizations and } \\
\text { Society }\end{array}$ \\
\hline $\begin{array}{l}\text { Gotsi, M.; Andriopoulos, } \\
\text { C.; Lewis, M.W.; Ingram, } \\
\text { A.E. (2010); }\end{array}$ & $\begin{array}{l}\text { Managing creatives: Paradoxical } \\
\text { approaches to identity regulation }\end{array}$ & Human Relations \\
\hline Pratt, J. (2001). & $\begin{array}{l}\text { Anthropology and political movements } \\
\text { (Class and ethnicity in Southern } \\
\text { Europe) }\end{array}$ & Journal of Mediterranean \\
\hline
\end{tabular}

Fonte: Elaborado pelos autores (2020).

A partir dos artigos selecionados, seguiu-se a aplicação dos próximos passos da metasíntese, com o objetivo de compreender a relação entre work passion e identidade.

\section{Passo 4: Extração e codificação dos dados}

A finalidade da meta-síntese é agrupar os principais pontos de cada artigo encontrado para que o pesquisador possa ter disponível um banco de dados que discuta seus interesses de pesquisa de forma breve e simples. Para que isso seja possível, o pesquisador precisa criar codificações para extrair os dados que julga importantes dos trabalhos encontrados na base de dados. Em relação as codificações, ressalta a importância desses códigos serem objetivos e claros para facilitarem o encontro das informações nas buscas, além de refletir os pressupostos do pesquisador diante dessa autonomia concedida (HOON, 2013).

Os dados coletados dos artigos encontrados nesta meta-síntese, foram organizados em uma planilha eletrônica a partir de nove grupos de divisão, são eles: Dados Gerais do Estudo (Autores, Título, periódico/congresso, ano, tipo de estudo); Objetivo dos autores (Objetivo geral, questão de pesquisa, principais contribuições); Fundamentação teórica (Compreensão sobre os conceitos de Work Passion e Identidade); Contexto do estudo realizado (País e contexto de pesquisa); Metodologia; Discussão; Limitações e principais contribuições. A fase descrita tem a finalidade de proporcionar uma visão geral dos artigos.

Neste momento o objetivo será responder ao problema de pesquisa dos estudos selecionados visando compreender a relação entre os temas de Work Passion e Identidade, portanto, para isso, foram criados dois códigos principais descritos a seguir: a) Conceito de Work Passion utilizado; b) Conceito de Identidade utilizado.

Revista Expectativa, Toledo/PR, v.20, n. 3, p. 131-151, jul./set., 2021. 
Considerando a pergunta de pesquisa escolhida neste estudo, o próximo passo tem por objetivo a contextualização de informações com o intuito de ajudar os leitores a compreenderem como são tratadas as abordagens de Work Passion e Identidade nos estudos encontrados.

\section{Passo 5: Análise em nível do estudo}

O estudo de uma meta-síntese tem o objetivo de identificar e construir ideias que possam contribuir ao desenvolvimento e melhoramento de teorias que possam explicar os fenômenos de maneira mais sólida e cada vez mais próximas da realidade. Nesse sentido, na sequência das fases propostas por Hoon (2013), a quinta fase visará expor as particularidades dos artigos selecionados para a meta-síntese.

O primeiro artigo selecionado foi escrito por Hahl e Mikulec (2018) e publicado na Australian Journal of Teacher Education. Este estudo visa analisar a experiência de 20 participantes matriculados em um curso internacional de inglês intermediário de preparação de professores secundários em uma Universidade da Finlândia. O artigo teve o objetivo de analisar as reflexões sobre a identidade do professor em desenvolvimento a fim de encontrar categorias de fatores que influenciaram o desenvolvimento da identidade dos professores. Os resultados indicam que o apoio especialmente de mentores e feedback dos alunos durante dois períodos de prática de ensino, e o a paixão de um professor por sua própria matéria, foram sentimentos adicionais para construir confiança na capacidade de ensino de cada um (HAHL; MIKULEC, 2018)

O segundo artigo selecionado foi escrito por Harvey e Shepherd (2016) e foi publicado na Internacional Journal of Cultural Studies. Neste estudo expõe-se as controvérsias em torno da identidade e diversidade na cultura dos jogos digitais ao qual tem aumentado o campo afetivo para os participantes dentro desta indústria criativa. Enquanto se trabalha em jogos digitais, a produção tem sido caracterizada como uma forma de trabalho apaixonado e afetivo, nesse sentido, o estudo busca examinar suas especificidades, particularmente a paixão que tem contribuindo no desenvolvimento. O caso analisado é uma iniciativa de mulheres nos jogos em Montreal ao qual os autores indicam como os vínculos entre afeto e competências, especificamente a criatividade e a técnica perpetuar uma não legitimação do trabalho das mulheres no design de jogos digitais (HARVEY; SHEPHERD, 2017)

Revista Expectativa, Toledo/PR, v.20, n. 3, p. 131-151, jul./set., 2021. 
O terceiro estudo escolhido para análise foi escrito por Stahl e Dale (2013) e publicado na Gender and Education. Este estudo busca compreender como apesar do desinteresse escolar dos meninos da classe trabalhadora em se engajar ativamente e ter sucesso em seu aprendizado, o que esse sucesso significa para sua construção identitária. Este artigo mostra como as práticas de aprendizagem se manifestam em subculturas de forma extracurriculares, apresentando as conclusões de duas atividades musicais relacionadas, DJ-ing e MC-ing e como esses os rapazes da escola no nordeste da Inglaterra decretam sua paixão através da agência criativa e de processos culturais expressivos com a música (STAHL; DALE, 2013).

O quarto estudo escolhido para análise foi escrito por DeNora (2013) e publicado no European Societies. Neste trabalho os processos de mercado podem ser vistos como estruturas que são moldadas pela forma, pelo fluxo e a troca de paixão, emoção e, muitas vezes, formas não marcadas de sensibilidade proporcionados por concertos de músicas por meio da cultura que transmitem. Estas associações permitem apegos emocionais e substâncias de identidade que podem se tornar parte integrante à distribuição artística e de maneiras que sejam socialmente consequentes. Estes temas são explorados por meio de um estudo de caso da produção e distribuição dos concertos de teclado de Beethoven no início do décimo nono Viena do século XIX. A autora descreve como a distribuição das obras de Beethoven ofereceram lições de gênero para produtores/distribuidores de música (compositores/distribuidores) levantados pelos intérpretes e consumidores de música de Beethoven (DENORA, 2013).

Por fim, o quinto estudo escolhido para análise foi escrito por Tayson Smith (2008) e foi publicado na Social Psychology Quarterly/American Sociological Association. Este caso tem o objetivo de como Work Passion apresenta seu papel emocional em conjunto com a mão de obra projetando respostas através de uma impressão clara baseada na dor, agonia, sofrimento, dos profissionais e como essa emoção acontece no trabalho em equipe dentro e fora dos bastidores, e isso se apresenta de três formas: a) as recompensas sociais pela paixão no trabalho; b) o trabalho apaixonado produzido em conjunto permite o tipo de amplitude que é difícil de alcançar no trabalho emocional solo, e c) como a work passion molda a identidade em dos indivíduos (SMITH, 2008).

Após exposta a análise individual de cada artigo, segue-se para o passo 6 descrito a seguir:

Revista Expectativa, Toledo/PR, v.20, n. 3, p. 131-151, jul./set., 2021. 


\section{Passo 6: Síntese em nível específico de cada caso}

Nesta etapa do trabalho, com as informações extraídas a nível individual de cada artigo, torna-se possível compreender como os conceitos de Work Passion e Identidade foram expostos, bem como se interligam.

Recomenda-se que nesta fase os resultados sejam apresentados por meio de quadro, que possibilite a visualização do assunto estudado. Para facilitar a visualização dos dados compreendidos e destacar as abordagens adotadas para discorrer sobre o assunto e suas interrelações (HOON, 2013), os artigos selecionados e analisados previamente em etapa anterior são dispostos resumidamente no Quadro 5:

Quadro 5 - síntese individual dos estudos

\begin{tabular}{|c|c|c|c|}
\hline Autor & Contexto & $\begin{array}{l}\text { Abordagem com Work } \\
\text { Passion }\end{array}$ & Abordagem com Identidade \\
\hline $\begin{array}{l}\text { Hahl, } \\
\text { K.; } \\
\text { Mikule } \\
\text { c, E. } \\
\text { (2018); }\end{array}$ & $\begin{array}{l}\text { Análise das experiências de } \\
20 \text { participantes } \\
\text { matriculados em um curso } \\
\text { internacional de inglês para } \\
\text { ensino médio programa de } \\
\text { preparação de professores } \\
\text { secundários em uma } \\
\text { universidade em Finlândia e } \\
\text { analisa as reflexões sobre } \\
\text { sua identidade de professor } \\
\text { em desenvolvimento. }\end{array}$ & $\begin{array}{l}\text { Os professores estudantes foram } \\
\text { unânimes em sua opinião de que } \\
\text { é importante para um professor } \\
\text { em demonstrar paixão e } \\
\text { entusiasmo por seu próprio } \\
\text { assunto de ensino, a fim de se } \\
\text { engajar e encorajar os alunos a } \\
\text { aprender o assunto. Eles } \\
\text { também consideraram esta } \\
\text { paixão pelo próprio assunto } \\
\text { como uma fator importante de } \\
\text { seu próprio profissionalismo. }\end{array}$ & $\begin{array}{l}\text { As descobertas demonstram que } \\
\text { o desenvolvimento de uma } \\
\text { identidade de professor é o } \\
\text { resultado de um processo ativo } \\
\text { de sucessos e desafios para se } \\
\text { tornar um professor. }\end{array}$ \\
\hline $\begin{array}{l}\text { Harvey } \\
\text {, A.; } \\
\text { Shephe } \\
\text { rd, T. } \\
\text { (2017); }\end{array}$ & $\begin{array}{l}\text { Mulheres nos jogos em } \\
\text { Montreal no trabalho das no } \\
\text { design de jogos digitais. }\end{array}$ & $\begin{array}{l}\text { As diferenças entre as } \\
\text { articulações da paixão por } \\
\text { mulheres que fazem jogos e } \\
\text { mobilizam dentro dos jogos a } \\
\text { cultura. Como uma força e } \\
\text { objetivos que moldam o } \\
\text { significado social e as fronteiras } \\
\text { culturais o afeta apoia e perpetua } \\
\text { uma noção que constitui e legitima } \\
\text { a participação de mulheres nesse } \\
\text { setor. }\end{array}$ & $\begin{array}{l}\text { O trabalho com jogos, } \\
\text { cultivado pela paixão e } \\
\text { dedicação à forma da mídia e } \\
\text { sua cultura, é tanto o assunto } \\
\text { do discursor afetivo } \\
\text { relacionado ao pertencimento } \\
\text { e identidade quanto o jogo. }\end{array}$ \\
\hline $\begin{array}{l}\text { Stahl, } \\
\text { G.; } \\
\text { Dale, } \\
\text { P. } \\
\text { (2013); }\end{array}$ & $\begin{array}{l}\text { O desinteresse dos meninos } \\
\text { da classe trabalhadora pela } \\
\text { educação e de baixo } \\
\text { rendimento escolar. Passam a } \\
\text { manifestar práticas de } \\
\text { aprendizagem em } \\
\text { subculturas extracurriculares } \\
\text { apresentando as conclusões } \\
\text { de duas atividades musicais: } \\
\text { DJ-ing e MC-ing. }\end{array}$ & $\begin{array}{l}\text { Articulação da paixão e } \\
\text { perseverança através da } \\
\text { atividade extracurricular nas } \\
\text { atividades musicais. }\end{array}$ & $\begin{array}{l}\text { A música proporcionou uma } \\
\text { fuga legítima dos problemas nas } \\
\text { ruas e uma maneira de lutar } \\
\text { contra a identidade imposta } \\
\text { através dos meios sociais. } \\
\text { Através da música eles foram } \\
\text { capazes de mudar entre } \\
\text { alternativas posições de } \\
\text { identidade. }\end{array}$ \\
\hline
\end{tabular}

Revista Expectativa, Toledo/PR, v.20, n. 3, p. 131-151, jul./set., 2021. 


\begin{tabular}{|c|c|c|c|}
\hline $\begin{array}{l}\text { DeNora } \\
\text {, T. } \\
(2013) \text {; }\end{array}$ & $\begin{array}{l}\text { Descrição da distribuição das } \\
\text { obras de Beethoven que } \\
\text { ofereceu lições de gênero } \\
\text { sobre } \\
\text { produtores/distribuidores de } \\
\text { música para consumidores de } \\
\text { música. Esse aprendizado } \\
\text { ocorreu por meio do mercado } \\
\text { da música de alta cultura } \\
\text { associada a exposições } \\
\text { cultural. }\end{array}$ & $\begin{array}{l}\text { O mercado da música e } \\
\text { processos podem ser vistos } \\
\text { como estruturas que estão } \\
\text { ambos de alguma forma existe } \\
\text { um fluxo e troca de paixão, } \\
\text { emoção e muitas vezes } \\
\text { despercebida formas de } \\
\text { sensibilidade. }\end{array}$ & $\begin{array}{l}\text { A estabilização da distribuição e } \\
\text { consumação padrões ao longo } \\
\text { do tempo no mercado da música } \\
\text { podem ser ligadas com produtos } \\
\text { artísticos. Estas associações } \\
\text { contribuem com as emoções } \\
\text { anexos a identidade que podem } \\
\text { tornar-se integrante para } \\
\text { artística distribuição e em } \\
\text { maneiras que são socialmente } \\
\text { consequentes. }\end{array}$ \\
\hline $\begin{array}{l}\text { Tayson } \\
\text { Smith, } \\
\text { R. } \\
\text { (2008); }\end{array}$ & $\begin{array}{l}\text { Escola profissionalizante que } \\
\text { treina homens para serem } \\
\text { lutadores gráficos em seu } \\
\text { local de prática e eventos } \\
\text { públicos. }\end{array}$ & $\begin{array}{l}\text { Este estudo teve o objetivo de } \\
\text { analisar o uso do trabalho } \\
\text { emocional para reencenar uma } \\
\text { luta agressiva entre dois artistas. } \\
\text { Em vez de ser algo restrito, foi } \\
\text { aberta ao público em função da } \\
\text { abertura emocional, uma troca } \\
\text { que define o total desempenho } \\
\text { dos lutadores, foi uma obscura } \\
\text { emoção aos bastidores, os traços } \\
\text { da emoção do trabalho nos } \\
\text { artistas, torna visível a emoção } \\
\text { sustenta que sustenta essa paixão } \\
\text { pelo trabalho. }\end{array}$ & $\begin{array}{l}\text { O trabalho emocional molda a } \\
\text { identidade nas performances } \\
\text { recreativas do corpo permitindo } \\
\text { os pesquisadores examinar a } \\
\text { associação entre o emocional de } \\
\text { trabalho e identidade como } \\
\text { forma dentro do contexto de } \\
\text { uma física recreativa atividade. }\end{array}$ \\
\hline
\end{tabular}

Fonte: Elaborado pelos autores (2020).

De maneira geral, os estudos apresentados cumprem com o objetivo ao qual foram selecionados. Esses estudos demonstram que existe Work Passion nas atividades propostas nos estudos de casos e essas contribuem na construção da identidade de seus indivíduos analisados promovendo mudanças em suas vidas.

\section{Passo 7: Construção da teoria}

Após a elaboração do quadro 6, seguindo os passos da autora (HOON, 2013) a construção de teorias da meta-síntese tem por objetivo aproximar-se dos fenômenos estudados por meio da interpretação dos dados e suas variáveis exploradas de maneiras distintas nos diferentes casos analisados. Com o propósito da construção de teoria em relação ao tema de estudo, contribuindo para as discussões na área, foi possível verificar a partir das análises individuais dos estudos uma relação entre o contexto em que o indivíduo atua, que afeta na paixão do indivíduo pela atividade e que tal significado traz à sua identidade. A relação entre as temáticas é representada por meio da Figura 1:

Revista Expectativa, Toledo/PR, v.20, n. 3, p. 131-151, jul./set., 2021. 
Figura 1 - Relação do Work Passion com a identidade organizacional

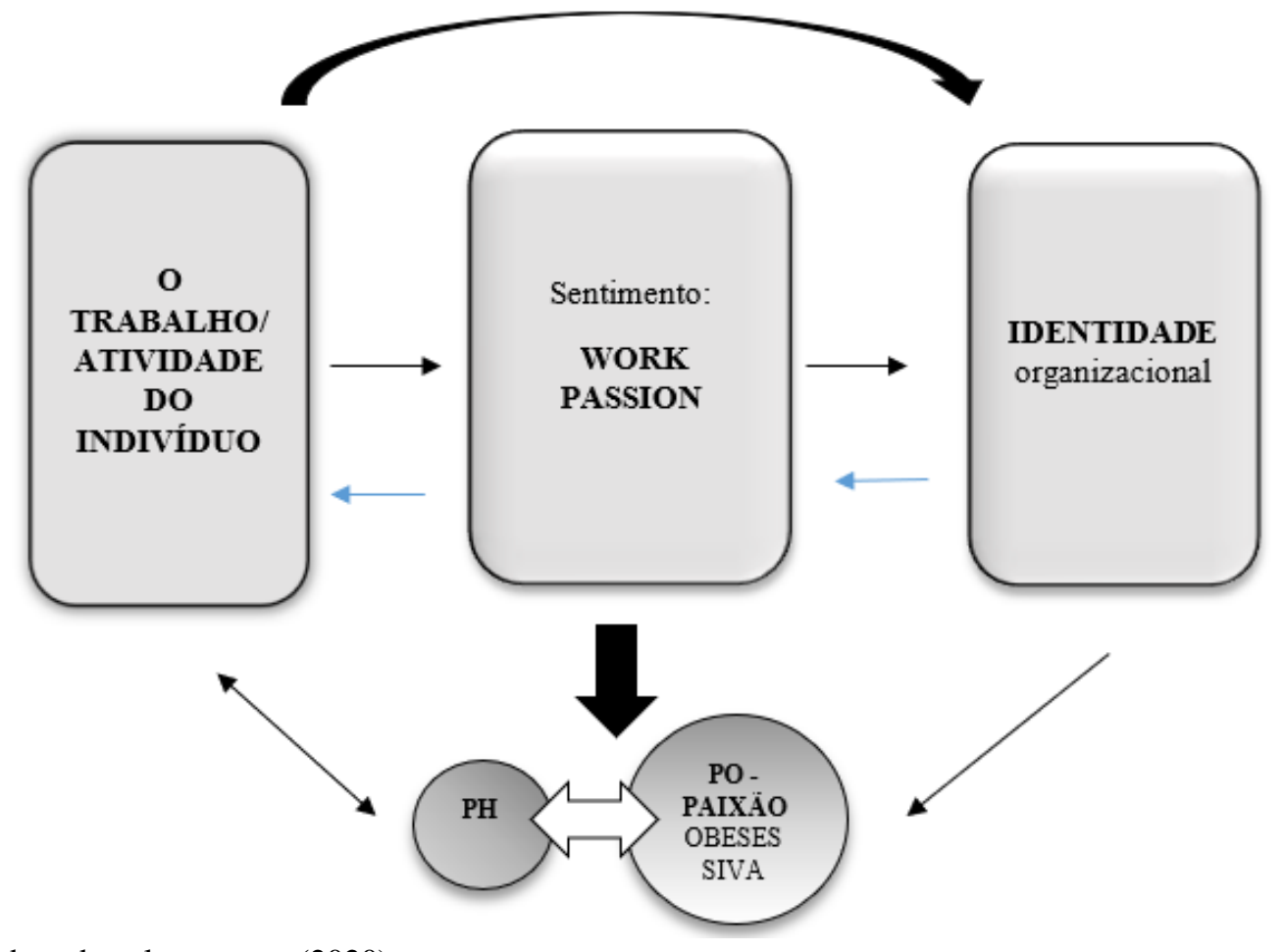

Fonte: Elaborada pelos autores (2020).

De acordo com a Figura 1, na sequência observada, são demonstradas três dimensões: da atividade (relação do indivíduo com o trabalho/atividade realizada); a da Work Passion (o sentimento de paixão que por ser harmonioso ou obsessivo) e a Identidade (a qual pode ou não ser influenciada pela paixão assim como pode influenciar a paixão). A relação entre a paixão pelo trabalho e a construção da Identidade se dá pela conexão que este adquire através do seu envolvimento com a atividade desenvolvida.

Essa paixão que pode, ou não, fazer conexão entre a atividade e entre a identidade, pode aparecer de duas formas, conforme a teoria de work passion esta relação pode dar-se de maneira harmoniosa ou de maneira obsessiva, nos estudos analisados verificou-se que há presença implícita das duas paixões. Ressalta-se que apesar de não haver somente um conceito de paixão pelo trabalho ou de identidade, as próprias características individuais influenciam o comportamento das pessoas impactando de forma positiva ou negativa essa internalização com a atividade desempenhada. Esse processo, dependendo de seu contexto e também de variáveis externas, pode resultar positivamente ou negativamente na vida das pessoas (VALLARAND et al., 2003).

Revista Expectativa, Toledo/PR, v.20, n. 3, p. 131-151, jul./set., 2021. 
Nos estudos analisados, há momentos em que a atividade afeta a paixão no trabalho auxiliando na construção da identidade, em outros, a identidade auxilia na paixão pelo trabalho. Todos então diretamente ligados com o contexto de vida e a atividade ou trabalho realizado nos artigos estudados, surgindo portanto, uma dinâmica entre os conceitos levando em consideração as mudanças, adaptações e reflexos da sociedade nas pessoas.

Portanto, as relações demonstradas nos artigos analisados entre os conceitos de work passion e identidade nesta meta-síntese, contribuem para explorar a teoria de relação entre ambas partindo do contexto da atividade ou trabalho executado. A partir disso, se organizam novos entendimentos para pensar as relações, qualidades e desafios a serem pensados em relação à paixão no trabalho buscando melhorar e transformar os ambientes de trabalho.

\section{Passo 8: Discussão}

A última fase proposta por Hoon (2013) é a discussão a respeito das convergências e divergências entre os artigos. Os estudos analisados, seguem uma ordem cronológica recente e chama-se atenção para o intervalo de tempo entre os artigos encontrados. Ou seja, verifica-se o pouco interesse de pesquisa entre a relação dos dois temas. Levando em consideração o exposto, cabe salientar que uma justificativa para tal fato deve-se ao filtro aplicado em que se buscou somente estudos de abordagem qualitativa, pois, fora este o exposto no protocolo de Hoon (2013).

Nessa meta-síntese os resultados encontrados vão de encontro com a teoria de Work passion, conforme o autor de base estudado Vallarand et al., (2003), que dispõe considerações a respeito de uma abordagem dualística quanto ao desenvolver de paixão pelo trabalho. A paixão harmoniosa fora vista em diversas situações, um exemplo foi do estudo de Hahl e Mikulec (2018) que a paixão de um professor por sua própria matéria, foram sentimentos que contribuíram para construir confiança na capacidade de ensino de cada um. Outro exemplo foi no estudo de Harvey e Shepherd (2017) que a paixão tem contribuído no desenvolvimento de jogos digitais, ou ainda no estudo de Stahl e Dale (2013) que os meninos da classe trabalhadora refletiram suas paixões pela atividade extracurricular através da agência criativa e de processos culturais expressivos com a música, assim, conforme descritos podem deixar a harmonia e direcionar-se a paixão obsessiva como demonstra-se no caso dos artistas que lutam com emoção em suas performances no estudo de Smith (2008). O estudo de DeNora (2013) não indicou

Revista Expectativa, Toledo/PR, v.20, n. 3, p. 131-151, jul./set., 2021. 
essas informações, mas diante do exposto percebe-se uma paixão harmoniosa em relação as atividades desenvolvidas.

No que diz respeito à construção da identidade dos indivíduos, no estudo Hahl e Mikulec (2018), verifica-se que a paixão pela atividade exercida contribuiu para moldar a identidade do indivíduo ao qual o estudo se direcionou a compreender a identidade dos estudantes. Nos demais destacou-se a paixão como principal característica para atividade desenvolvida.

Além das análises feitas referente aos conceitos propostos, verificou-se no artigo de Harvey e Shepherd (2017) o alento em relação ao gênero, pois com a paixão presente na identidade das mulheres, ajudam a continuarem desenvolvendo jogos e lidarem como todos os desafios impostos a elas neste ambiente masculino.

Outro fator que chama atenção, é em relação aos temas não convencionais aos quais a pesquisa nos direcionou, como o artigo Harvey e Shepherd (2017) em que as mulheres desenvolvem jogos digitais em Montreal, no artigo de de Stahl e Dale (2013) em que é feita uma análise exploratória através da produção e distribuição dos concertos de teclado de Beethoven em Viena do século XIX. Ou ainda no estudo de Smith (2008) em relação de paixão desenvolvido pelos homens que atuam em lutas de performance como artistas demonstrando grande paixão na atividade.

Portanto, o modelo apresentado na Figura 1, aborda como a paixão pelo trabalho influencia a construção identitária do indivíduo, assim como sua relação com a atividade desenvolvida, e como isso pode afetar nas organizações em que atuam. De acordo com os achados, o processo de desenvolvimento da paixão pelo trabalho afeta o comportamento das pessoas, consistindo na articulação e interferência na maneira de lidar com seus sentimentos nas organizações. Esse processo dinâmico passa a promover a melhora nas condições e relações de trabalho dentro das organizações, desenvolvendo novas motivações, decisões como também contribuindo na identidade das pessoas assim como sua permanência em determinada atividade.

\section{CONSIDERAÇÕES FINAIS}

Este estudo teve como objetivo analisar como a work passion afeta a identidade do indivíduo a partir da metodologia de meta-síntese proposta por Hoon (2013), tratando-se de

Revista Expectativa, Toledo/PR, v.20, n. 3, p. 131-151, jul./set., 2021. 
alguns aspectos subjetivos presentes na vida dos trabalhadores, como é o caso da paixão pelo trabalho.

A partir da metodologia de meta-síntese proposta por Hoon (2013) aplicou-se os termos escolhidos para busca foram “Work Passion*” AND "Identity” AND "Study Case resultando um total de 17 artigos nas seguintes bases de dados: Web of Science; Scopus; Scielo e Spell. A partir dessa busca, focou-se em cinco estudos de caso qualitativos para análise dos conceitos escolhidos.

A partir dessa análise, até o momento, não é possível concretizar que exista uma unificação dos conceitos, no entanto espera-se que este trabalho tenha contribuído para alcançar e chamar atenção para a necessidade de expandir o uso dos estudos de casos em trabalhos qualitativos na relação entre a temática explorada. Por fim, este estudo pode proporcionar um aumento do conhecimento a respeito da teoria de work passion nas organizações.

Não esgotando as possibilidades de estudo do tema, sugere-se para pesquisas futuras, a inclusão de outras bases de dados com o objetivo de expandir o número de artigos analisados para a meta-síntese. Outra sugestão seria realizar um estudo com foco em somente um dos conceitos, aumentando o portfólio dos artigos alcançando outros resultados, além da possibilidade de estudar outros sentimentos relacionadas às emoções dos indivíduos como empatia, afetos e humor.

\section{REFERÊNCIAS}

AKEHURST, S.; OLIVER, E. J. Obsessive passion: a dependency associated with injuryrelated risky behaviour in dancers. Journal of sports sciences, v. 32, n. 3, p. 259-267, 2014.

CASTELLS, M. Communication power. OUP Oxford, 2013.

CLOT, Y. A função psicológica do trabalho. Petrópolis: Vozes, 2007.

CLOT, Y. Trabalho e poder de agir. Belo Horizonte: Fabrefactum, 2010.

CRESWELL, J. W. et al. Qualitative research designs: Selection and implementation. The counseling psychologist, v. 35, n. 2, p. 236-264, 2007.

CRESWELL, J. W. Qualitative inquiry and research design: Choosing among five approaches, v. 2, 2010.

Revista Expectativa, Toledo/PR, v.20, n. 3, p. 131-151, jul./set., 2021. 
DECI, E. L.; RYAN, R. M. The" what" and" why" of goal pursuits: Human needs and the self-determination of behavior. Psychological inquiry, v. 11, n. 4, p. 227-268, 2000.

DENORA, T. Musicians make markets: Aestheticising music distribution in Beethoven's Vienna. European Societies, v. 15, n. 2, p. 212-228, 2013.

DONAHUE, E. G.; RIP, B.; VALLERAND, R. J. When winning is everything: On passion, identity, and aggression in sport. Psychology of Sport and Exercise, v. 10, n. 5, p. 526-534, 2009.

FOREST EUROPE. Status \& Trends in Sustainable Forest Management in Europe. In: FOREST EUROPE (ORGANIZATION), 2010. Proceedings [...]. State of Europe's Forests, Liaison Unit Oslo, 2010.

HAHL, K.; MIKULEC, E. Student reflections on teacher identity development in a year-long secondary teacher preparation program. Australian Journal of Teacher Education, v. 43, n. 12, p. 4, 2018.

HARVEY, A.; SHEPHERD, T. When passion isn't enough: gender, affect and credibility in digital games design. International Journal of Cultural Studies, v. 20, n. 5, p. 492-508, 2017.

HOON, C. Meta-synthesis of qualitative case studies: An approach to theory building. Organizational Research Methods, v. 16, n. 4, p. 522-556, 2013.

LOURENÇO DE ABREU, L. Reconstrução de uma identidade estilhaçada: Um defeito de cor de Ana Maria Gonçalves. In: COLÓQUIO "ATÉ ÀS RAÍZES DA LUSOFONIA", 2020. Anais [...]. Belgica, Université de Gand, 2020.

MORIN, E. M.; DASSA, C. Characteristics of a meaningful work. Montréal: HEC, 2006.

PINHO, Isabel et al. Determinantes na adoção e recomendação de software de investigação qualitativa: estudo exploratório. Internet Latent Corpus Journal, v. 4, n. 2, p. 91-102, 2014.

SIMPSON, B.; CARROLL, B. Re-viewing 'role' in processes of identity construction. Organization, v. 15, n. 1, p. 29-50, 2015.

SMITH, R. Tyson. Passion work: The joint production of emotional labor in professional wrestling. Social Psychology Quarterly, v. 71, n. 2, p. 157-176, 2008.

SOUSA, C. F.; BRANCO, M. Z. P. C. Meta-síntese: uma revisão da literatura-contributos para o conhecimento e para os cuidados de enfermagem. Enfermagem em Foco, v. 4, n. 2, 2013.

STAHL, G.; DALE, P. Success on the decks: Working-class boys, education and turning the tables on perceptions of failure. Gender and Education, v. 25, n. 3, p. 357-372, 2013. 
STAKE, R. E. Qualitative Case studies. In: DENZIN, N. K.; LINCOLN, Y. S. (Eds.). The Sage handbook of qualitative research. London: Sage Publications, 2005.

STAKE, R. E. The art of case study research. London: Sage Publications, 1995.

VALLERAND, R, J. et al. Passion in sport: A look at determinants and affective experiences. Journal of Sport and Exercise Psychology, v. 28, n. 4, p. 454-478, 2006.

VALLERAND, R. J. On the psychology of passion: In search of what makes people's lives most worth living. Canadian Psychology/Psychologie Canadienne, v. 49, n. 1, p. 1, 2008.

VALLERAND, R. J.; HOULFORT, N.; FORES, J. Passion at work. Emerging perspectives on values in organizations, p. 175-204, 2003.

WRZESNIEWSKI, Amy et al. Jobs, careers, and callings: People's relations to their work. Journal of research in personality, v. 31, n. 1, p. 21-33, 1997.

WRZESNIEWSKI, A.; DUTTON, J. E.; DEBEBE, G. Interpersonal sensemaking and the meaning of work. Research in organizational behavior, v. 25, p. 93-135, 2003.

YIN, R. K. Case study research: Design and methods. 4th edition. In: THOUSAND OAKS, 4., 2009. Proceedings [...]. United States: Library of Congress Cataloguing-in-Publication Data. 2009. 